\title{
Editorial
}

\section{Do ensino da teoria à transmissão da prática clínica na Universidade e noutros lugares}

From theory teaching to clinical practice transmission at the University and elsewhere

Estamos às vésperas do VIII Congresso Internacional de Psicopatologia Fundamental e do XIV Congresso Brasileiro de Psicopatologia Fundamental. Pela primeira vez foi preciso prepará-lo inteiramente sem a liderança incansável do fundador da Associação Universitária de Pesquisa em Psicopatologia Fundamental - o Professor Dr. Manoel Berlinck - e de sua colaboradora, nossa colega a dra. Ana Cecília Magtaz.

A psicopatologia fundamental, com origem nos trabalhos de Pierre Fédida na França, propõe o acolhimento de um pathos, de um sofrimento, que a clínica recolhe em um campo transdisciplinar, que interessa a todo o campo da medicina, da psiquiatria e das ciências humanas. Embora a psicanálise seja a

* Universidade Federal do Rio de Janeiro - UFRJ (Rio de Janeiro, RJ, Brasil). Presidente do Congresso da AUPPF-2018. 
referência mais importante, nos dias de hoje, da psicopatologia fundamental, dialogamos com as ciências sociais, com a literatura, poesia, medicina, psiquiatria e com a psicologia científica.

O tema proposto neste VIII Congresso Internacional de Psicopatologia Fundamental e XIV Congresso Brasileiro de Psicopatologia Fundamental A clínica na Universidade e além - vai abordar as práticas clínicas que se desenvolvem em nome da pesquisa na universidade. A questão que se coloca é: o método clínico suporta bem as adaptações que sua aplicação no campo da pesquisa universitária exigem?

Para responder a uma questão como essa é preciso recorrer ao exame das práticas clínicas que são desenvolvidas nos diferentes espaços institucionais: na saúde, no hospital, na assistência social, na escola, no judiciário.

Como reconhecer essas práticas clínicas, diferenciando-as de outras práticas que também frequentam os mesmos ambientes institucionais, e que se destinam a outras finalidades mais identificadas com a gestão de recursos humanos, redução de conflitos de interesse e de custos?

A questão da qualidade permite identificar o método clínico, distinguindo-o de outras abordagens do mal-estar e foi o tema que nos ocupou no último congresso. Na ocasião de sua organização, Manoel Berlinck ainda estava à frente da condução desta pergunta acerca da qualidade do método clínico. Em reconhecimento ao seu papel na instigação de questões atinentes ao exercício da clínica no campo da psicopatologia, a comissão organizadora deste novo congresso pensou em avançar na direção de uma avaliação das práticas clínicas associadas à pesquisa, ao pensar, ao questionamento e à renovação destes em conformidade com os desafios que enfrenta a subjetivação na contemporaneidade.

Cabe ressaltar que uma prática clínica é um tratamento do real pelo simbólico. Seu instrumento é o ato de dizer aquilo que é o mais íntimo, introduzindo o indizível no campo da fala e da linguagem. Todo dizer encontra um impossível de dizer, que se manifesta tantas vezes como mal-entendido, pois o dizer também é a experiência de dizer mais do que quis dizer. Não se trata, portanto, da aplicação de uma técnica - a associação livre, por exemplo. Trata-se de abordar o que não se pode dizer por meio de um forçamento: a interpretação. Interpretar é produzir máscaras, semblantes do real. O semblante é um discurso, uma mistura de razão e sensibilidade. Dizendo de outro modo, uma mistura da linguagem ao que o corpo tem de mais real. Semblantes são discursos que fabricamos para 
abordar o real da pulsão, o indizível do sofrimento e a angústia que habita todo aquele que fala.

Pode a Universidade ensejar a produção e a renovação de práticas clínicas? Ou seria a Universidade um mero repositório de um saber caduco, reproduzido à exaustão por acadêmicos empoeirados, recolhidos em seus gabinetes e bibliotecas, distantes de todos os lugares onde a vida pulsa?

Não é esta a experiência dos professores, pesquisadores, doutorandos, mestrandos e graduandos na universidade brasileira. Nossos projetos de pesquisa, cada vez mais, se debruçam sobre os impasses que a clínica em extensão — ou, melhor dizendo, a psicanálise aplicada em instituições — nos convida a enfrentar e resolver. $\mathrm{O}$ que nos desafia a intervir é o sofrimento, o sintoma, o mal-estar na civilização em suas mais novas manifestações. Existe uma urgência no sujeito e no laço social que nos convida a sair da biblioteca e inventar soluções inovadoras.

A urgência subjetiva habita a pesquisa na clínica. Estudantes de graduação nos trazem as experiências inquietantes que os atravessam nos seus estágios para pensá-las em suas iniciações científicas e monografias de fim de curso. Mestrandos e doutorandos voltam à universidade, em busca de soluções para os difíceis impasses que encontram em suas práticas junto aos doentes, aos técnicos e às famílias nos hospitais. Ou na mediação de conflitos em casos de violação de direitos no campo da assistência social. Ou, ainda, na dissolução dos impasses que a infância e a juventude - comum ou transgressora — encontra na relação com o saber, com pais e mestres ou, mais além, com a lei e as medidas que visam reeducá-los.

Estas foram algumas das questões que motivaram a Comissão Organizadora do VIII Congresso Internacional e do XIV Congresso Brasileiro de Psicopatologia Fundamental a convocar seus membros e participantes externos a enviar seus trabalhos e discuti-los neste encontro no Rio de Janeiro, no Hotel South America, nos dias 7, 8 e 9 de setembro de 2018.

Citação/Citation: Santos, T. C. (2018, setembro). Editorial. Revista Latinoamericana de Psicopatologia Fundamental, 21(3), 427-430. http://dx.doi.org/10.1590/1415-4714.2018v$21 \mathrm{n} 3 \mathrm{p} 427.1$

Editores do artigo/Editors: Profa. Dra. Ana Maria Rudge e Profa. Dra. Sonia Leite

Recebido/Received: 17.07.2018 / 07.17.2018 Aceito/Accepted: 20.07.2018 / 07.20.2018 
Copyright: (C) 2009 Associação Universitária de Pesquisa em Psicopatologia Fundamental/ University Association for Research in Fundamental Psychopathology. Este é um artigo de livre acesso, que permite uso irrestrito, distribuição e reprodução em qualquer meio, desde que o autor e a fonte sejam citados / This is an open-access article, which permits unrestricted use, distribution, and reproduction in any medium, provided the original authors and sources are credited.

\section{Tania Coelho dos Santos}

Pós-Doc no Départmant de Psychanalyse da Universidade Paris-VIII, França; Doutorado em Psicologia Clínica pela Pontifícia Universidade Católica do Rio de Janeiro - PUC-RJ (Rio de Janeiro, RJ, Brasil); Professora Associada do Programa de Pós-Graduação em Teoria Psicanalítica do Instituto de Psicologia da Universidade Federal do Rio de Janeiro - UFRJ (Rio de Janeiro, RJ, Brasil); Coordenadora do Núcleo Sephora de Pesquisa sobre o Moderno e o Contemporâneo (Rio de Janeiro, RJ, Brasil); Membro da Escola Brasileira de Psicanálise (Rio de Janeiro, RJ, Brasil), da Associação Mundial de Psicanálise e da Associação Universitária de Pesquisa em Psicopatologia Fundamental (São Paulo, SP, Brasil)

Rua Prof. Julio Lohman, 430 - Joatinga

22611-170 Rio de Janeiro, RJ, Brasil

taniacs@openlink.com.br

This is an open-access article, which permits unrestricted use, distribution, and reproduction in any medium for non-commercial purposes provided the original authors and sources are credited. 